\title{
THE POSSIBLE FUTURE BEHAVIOUR OF BERENDON GLACIER, CANADA-A FURTHER STUDY
}

\author{
By David A. Fisher* and Stephen J. Jones \\ (Department of Energy, Mines and Resources, Inland Waters Branch, Ottawa, Ontario, \\ Canada)
}

\begin{abstract}
Untersteiner and Nye (1968) calculated the possible future movement of Berendon Glacier, B.C. These calculations are repeated using much improved data and a slightly different method for computing the datum state. The predictions that result are very similar to those found in the earlier work. It is concluded, however, from mass-balance data, that the chance of the glacier rising sufficiently in the next 25 years to be a danger to the mining installations situated near the snout of the glacier is much greater than was previously considered. The sensitivity of the theory to changes in input data is discussed.

RÉsumé. Le comportement futur possible du glacier Berendon, Canada -étude complémentaire. Untersteiner et Nye (1968) ont calculé le mouvement futur possible du glacier Berendon en Colombie Britannique. Ces calculs sont repris à partir de données plus sûres et d'une méthode légèrement différente pour calculer l'état initial. Les prévisions qui en résultent sont très semblables à celles trouvées dans le travail précédent. Cependant des données sur le bilan de masse permettent de conclure que les chances pour que ce glacier progresse au cours des 25 prochaines années au point de menacer les installations minières situées près de son front sont beaucoup plus grandes qu'on ne l'avait considéré. La sensibilité de la méthode à des change-
ments dans les données de base est discutée.

Zusammenfassung. Das mögliche zukünftige Verhalten des Berendon Glacier, Kanada-eine weitere Untersuchung Untersteiner und Nye (1968) berechneten das mögliche künftige Verhalten des Berendon Glacier in British Columbia. Diese Berechnungen werden hier wiederholt, wobei stark verbesserte Werte und eine leicht unterschiedliche Methode verwendet werden, um den Grundzustand zu ermitteln. Die sich ergebenden Voraussagen sind denjenigen, die in der früheren Arbeit gefunden wurden, sehr ähnlich. Es wird jedoch auf Grund der Massenhaushaltswerte darauf geschlossen, dass die Möglichkeit für ein so hohes Ansteigen des Gletschers in den nächsten 25 Jahren, dass er die Grubeninstallationen nahe der Gletscherzunge gefährden kann, viel grösser ist als ursprünglich angenommen. Die Empfindlichkeit der Theorie gegenüber Veränderungen der Eingangsdaten wird diskutiert.
\end{abstract}

\section{INTRODUCTION}

Berendon Glacier (lat. $5^{\circ}{ }^{\circ} 5^{\prime}$ N., long. $130^{\circ} 05^{\prime}$ W.) is situated in the Coast Mountains of British Columbia, Canada. Untersteiner and Nye (1968) (referred to in this paper as $\mathrm{U}-\mathrm{N}$ ) calculated the frequency response of this glacier and made predictions about its possible future movement. They were particularly concerned to see whether, in the next 40 years or so, the glacier was likely to advance sufficiently to be a danger to the mining installations of the Granduc Operating Company, which are situated near the snout of the glacier. The data they used, however, "necessarily involved a good deal of guesswork". Since the publication of U-N, detailed field measurements have become available (Rogerson, in press; Stanley, in press). It was decided, therefore, to repeat the earlier calculations using these improved data, to see how they affected the predictions and also to see how sensitive the theory is to changes in the input data.

\section{Procedure for Setting UP The Datum State}

The theory used, which is concerned only with changes in the glacier that are small compared with the overall dimensions, is developed in five papers (Nye, ig6o, r963[a], $\left.\mathrm{r}_{963}[\mathrm{~b}], \mathrm{r}_{965}[\mathrm{~b}], \mathrm{r}_{96}[\mathrm{c}]\right)$. The nomenclature used here is the same as that used in those papers. The datum glacier is characterized by three functions $B_{0}(x), \mathbf{c}_{0}(x), \mathbf{D}_{0}(x)$ where $x$ is a coordinate denoting distance down the glacier, the functions being, respectively, the width of the glacier in a datum state, the velocity of kinematic waves multiplied by $B_{0}$, and the diffusivity of kinematic waves multiplied by $B_{0}$. The suffix zero signifies the datum state.

\footnotetext{
* Now at Department of Astronomy, Victoria University of Manchester, Manchester, England.
} 
To estimate these functions for the Berendon Glacier we used the same procedure as that described in Nye ( $196_{3}[\mathrm{~b}]$ and $\left.1965[\mathrm{~b}]\right)$. Since the essential difference between this paper and U-N is the data used in determining $B_{0}(x), \mathbf{c}_{0}(x)$ and $\mathbf{D}_{0}(x)$, we now consider in detail the data used in the two cases.

The data used by $\mathrm{U}-\mathrm{N}$ were as follows:

I. Three I:I2 ooo topographical maps for 1949, I956 and I963. None of these maps, however, showed the upper reaches of the accumulation zone, and here $\mathrm{U}-\mathrm{N}$ had to resort to a $1: 250$ ooo map.

2. The cross-sectional area, $S_{0}(x)$, of the glacier. The bedrock topography was not known and had to be inferred from cross-sections of the valleys in the lower part of the glacier and estimated in the upper part.

3. The variation of the net mass balance, $a$, with $x$, estimated by comparing Berendon with eight other glaciers along the coast between Washington and Alaska.

The data used in this work were:

I. A new I : 10 ooo map made in 1968 , which has closer contour intervals ( $10 \mathrm{~m}$ ) than any previous map and which gives complete coverage of the upper accumulation areas. From this, $B(x)$ is determined and $B(x)$ is assumed to be $B_{0}(x)$.

2. Net mass-balance data for 1967,1968 , and 1969 (Rogerson, in press; Stanley, in press). These are shown as a function of $x$ in Figure I. For I $_{9} 67 /$ i 968 the data are extrapolated for $x<1.8 \mathrm{~km}$. From these measurements, a datum state mass balance is derived by taking the mean of the two years' results and displacing it downwards by $0.72 \mathrm{~m}$ to satisfy the condition $\int_{0}^{L} a_{0} B_{0} d x=0$. (Nye, $\mathrm{I}_{9} 6_{3}[\mathrm{~b}]$ ), and this is also shown in Figure $\mathbf{I}$.

3. Measured velocities for the bottom half of the glacier for $1967 / 68$ and $1968 / 69$.

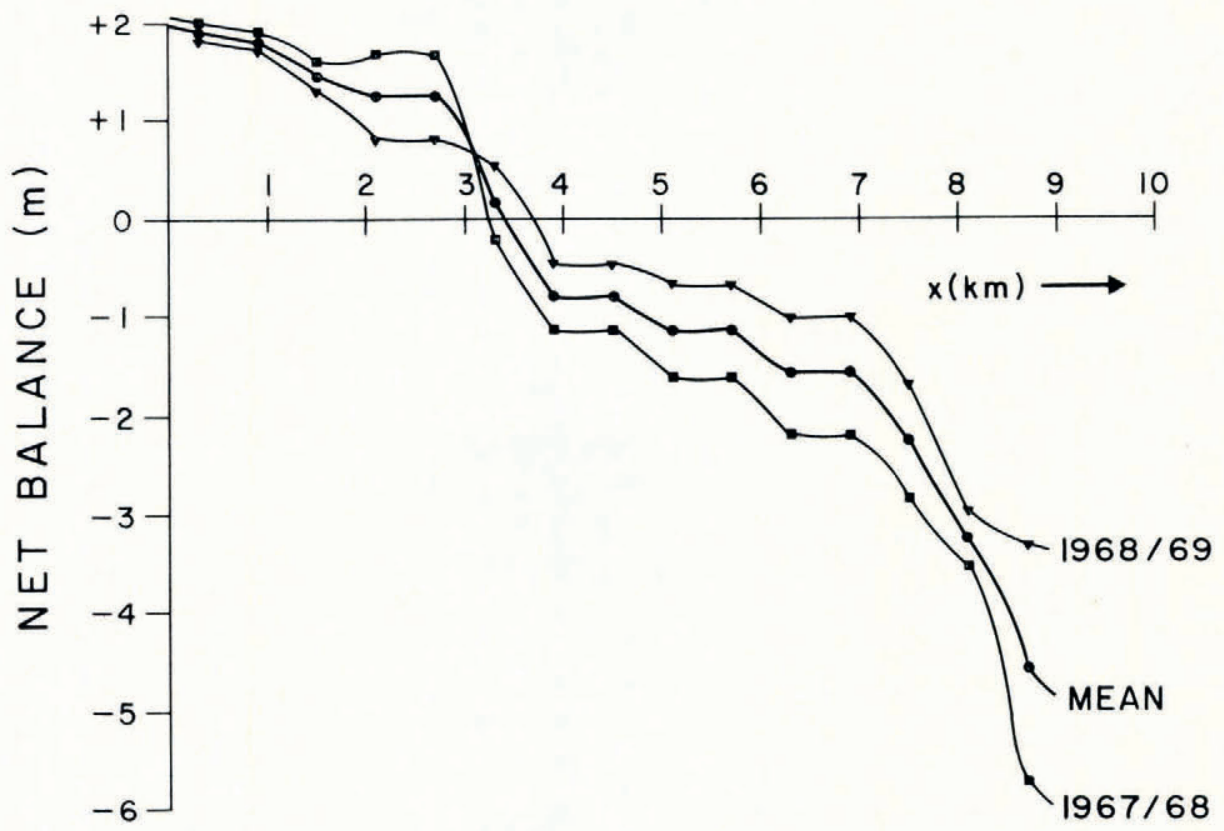

Fig. I. Mass-balance data for Berendon Glacier. The data for 1967/68 and $1968 / 69$ are shown, together with the mean of these and also the datum state chosen. 
A slightly different method was used to obtain the datum velocities $u_{0}(x)$. U-N inferred their $u_{0}(x)$ 's from the equation $\mathbf{q}_{0}=S_{0} u_{0}$, using their estimate of $S_{0}$ and a value of $\mathbf{q}_{0}$ given by $\mathbf{q}_{0}=\int_{0}^{x} a_{0} B_{0} d x$. The present authors used measured values of $u(x)$ for the lower part of the glacier and then multiplied each value by $u_{0}(L) / u(L)$ where $x=L$ is the snout of the glacier, in a manner suggested by Nye $\left(1_{9} 6_{3}[\mathrm{~b}]\right)$. In this procedure, $u_{0}(L)$ is determined from the equation

$$
u_{0}(L) \tan \theta_{0}=-a_{0}(L)
$$

which holds for a wedge-shaped terminus of wedge-angle $\theta_{0}$. If $\alpha_{0}$ is the surface slope at the terminus and $\beta_{0}$ is the bedrock slope, then $\theta_{0}=\alpha_{0}-\beta_{0}$. In our case $a_{0}(L)$ is fixed, $\alpha_{0}=\mathrm{II}^{\circ}$ was taken from the r 968 map and $\beta_{0}=2.5^{\circ}$ was estimated by first determining the depth of the ice, $h$, at $x=8400 \mathrm{~m}$ from the equation for a parabolic profile, $S=\frac{2}{3} h B_{0}$, using U-N's value of $S$, the cross-sectional area of the glacier. Hence $u_{0}(L)$ was determined from Equation $\mathrm{I}$. For our data, $U_{0}(L) / U(L)=$ I.o, by coincidence, which means that the snout is currently in equilibrium. To determine the datum velocities for the upper half of the glacier, the values used by $\mathrm{U}-\mathrm{N}$ were taken and moved up the velocity axis so that they joined up smoothly with the values found above for the lower half of the glacier. The resultant values of $u_{0}(x)$ are given in Table I.

Table I. Datum state values calculated for Berendon Glacier

\begin{tabular}{|c|c|c|c|c|c|c|c|c|}
\hline $\begin{array}{l}x \\
\mathrm{~m}\end{array}$ & $\begin{array}{c}z \\
\mathrm{~m}\end{array}$ & $\begin{array}{l}B_{0} \\
\mathrm{~m}\end{array}$ & $\begin{array}{c}\alpha_{0} \\
\operatorname{deg}\end{array}$ & $\begin{array}{c}a_{0} \\
\text { m year-1 }\end{array}$ & $\begin{array}{l}\mathbf{q}_{0} \times \mathrm{IO}^{-4} \\
\mathrm{~m}^{3} \text { year }^{-1}\end{array}$ & $\begin{array}{l}\mathbf{D}_{0} \times \mathrm{IO}^{-7} \\
\mathrm{~m}^{3} \text { year }^{-1}\end{array}$ & $\begin{array}{c}u_{0} \\
\text { m year-1 }\end{array}$ & $\begin{array}{l}\mathbf{c}_{0} \times \mathrm{IO}^{-4} \\
\mathrm{~m}^{2} \text { year }^{-1}\end{array}$ \\
\hline o & 1862 & 9800 & I5 & I. 30 & o & o & o & o \\
\hline 600 & 1710 & 10810 & $14 \cdot 3$ & 1.15 & $75^{6}$ & 8.8 & 18 & 58.4 \\
\hline 1200 & 1581 & 9460 & 12.2 & 0.95 & ${ }^{1} 47^{2}$ & 20.4 & 25 & 70.9 \\
\hline 1800 & 1459 & 6310 & 11.5 & 0.70 & 1 785 & 26.3 & 25 & $4^{8.2}$ \\
\hline 2400 & ${ }^{1} 4^{18}$ & $375^{\circ}$ & $3 \cdot 9$ & 0.55 & I 979 & $87 \cdot 3$ & 27 & 30.9 \\
\hline 3000 & 1345 & 3300 & 6.9 & 0.20 & 2057 & $5^{1.0}$ & 31 & $3^{1.2}$ \\
\hline 3600 & 1287 & $279^{\circ}$ & $5 \cdot 5$ & -1.10 & I 989 & 62.0 & 37 & 31.8 \\
\hline 4200 & I 247 & 2360 & $3 \cdot 7$ & -1.50 & I $79^{\circ}$ & 83.0 & $4^{6}$ & $3^{2.9}$ \\
\hline $\begin{array}{l}4800 \\
400\end{array}$ & I 193 & 2040 & $5 \cdot 2$ & - - .60 & I $59^{\circ}$ & $5^{2.4}$ & 54 & 33.7 \\
\hline 5400 & $114^{8}$ & I 880 & $4 \cdot 3$ & -1.80 & ${ }^{1} 39^{1}$ & $55 \cdot 5$ & 62 & 35.2 \\
\hline 6600 & 1 099 & 1760 & 4.7 & -2.00 & I I 86 & $43 \cdot 3$ & 45 & 24.0 \\
\hline $\begin{array}{l}6000 \\
7200\end{array}$ & $104 \mathrm{I}$ & 1490 & $5 \cdot 5$ & -2.30 & $9^{8 \mathrm{I}}$ & 30.6 & $5^{0}$ & 22.6 \\
\hline 7800 & 977 & 1620 & 6.1 & -2.55 & 760 & 21.3 & 60 & 29.6 \\
\hline 8400 & 810 & I $33^{\circ}$ & ${ }^{15} 5$ & -3.45 & $5^{61}$ & 6.1 & 60 & $24 \cdot 3$ \\
\hline 8400 & 720 & $85^{\circ}$ & 8.5 & -4.60 & 367 & $7 \cdot 4$ & 30 & 7.8 \\
\hline 8900 & & 700 & 11.0 & -5.95 & 0 & 0 & 29 & 2.0 \\
\hline $\begin{array}{l}\text { dista } \\
\text {, heig } \\
\text {, widt } \\
\text { slope } \\
\text { mea }\end{array}$ & $\begin{array}{l}\text { from ho } \\
\text { f surface } \\
\text { glacier } \\
\text { surface } \\
\text { lance in }\end{array}$ & $\begin{array}{l}\text { of glaci } \\
\text { ove mea }\end{array}$ & level & $\begin{aligned} \mathbf{q}_{0} & =\int_{0}^{x} a_{0} \\
\mathbf{D}_{0} & =3 \mathbf{q}_{\mathrm{o}} \\
u_{\mathrm{o}} & =\text { ice } \\
\mathbf{c}_{\mathrm{o}} & =3 B_{0}\end{aligned}$ & $\begin{array}{l}{ }_{0} d x=\text { disch } \\
\text { ot } \alpha_{0}=\text { diff } \\
\text { elocity } \\
\text { (except ne }\end{array}$ & $\begin{array}{l}\text { arge } \\
\text { sion coeffici } \\
\text { ir terminus) }\end{array}$ & $\begin{array}{l}\mathrm{t} \times B_{0} \\
\text { wave ve }\end{array}$ & ity $\times B_{0}$ \\
\hline
\end{tabular}


With these data, a datum-state glacier was set up and the result is shown in Table I. This may be compared with table I of U-N (p. 207). The major difference is in the velocity column $u_{0}$ where our velocities are in general, lower than U-N's. This causes a corresponding fall in $\mathbf{c}_{0}$, because $\mathbf{c}_{0}={ }_{3} B_{0} u_{0}$ (except near the terminus) for a parabolic channel (Nye, $1965[\mathrm{a}]$, table IIIc, p. 678).

\section{COMPARISON OF THE PREDICTIONS}

The theory given by Nye ( $1963[\mathrm{~b}]$ ) connects the time variation in the mean mass balance $a_{\mathrm{I}}(t)$, with the time variation in the thickness of the glacier, $h_{1}(t)$, at the particular value of $x$ through the equation

$$
a_{\mathrm{I}}(t)=\lambda_{0} h_{\mathrm{I}}(t)+\lambda_{\mathrm{I}} \dot{h}_{\mathrm{I}}(t)+\lambda_{2} \ddot{h}_{\mathrm{I}}(t)+\ldots,
$$

where the dots denote differentiation with respect to time, and the $\lambda$ 's are numerical coefficients that may be computed for the particular $x$ in question. The values of the $\lambda$ 's at $x=855^{\circ} \mathrm{m}$ (corresponding to the location of the portal to the mine) were computed by the method described by Nye (1963 [b]) using the functions $B_{0}(x), c_{0}(x), D_{0}(x)$ as input data. The values obtained for $\lambda_{0}, \lambda_{1}$ and $\lambda_{2}$ are shown in Table II compared with those found by U-N. The

TABle II. Summary of the Results of this PAPER COMPAREd to U-N's

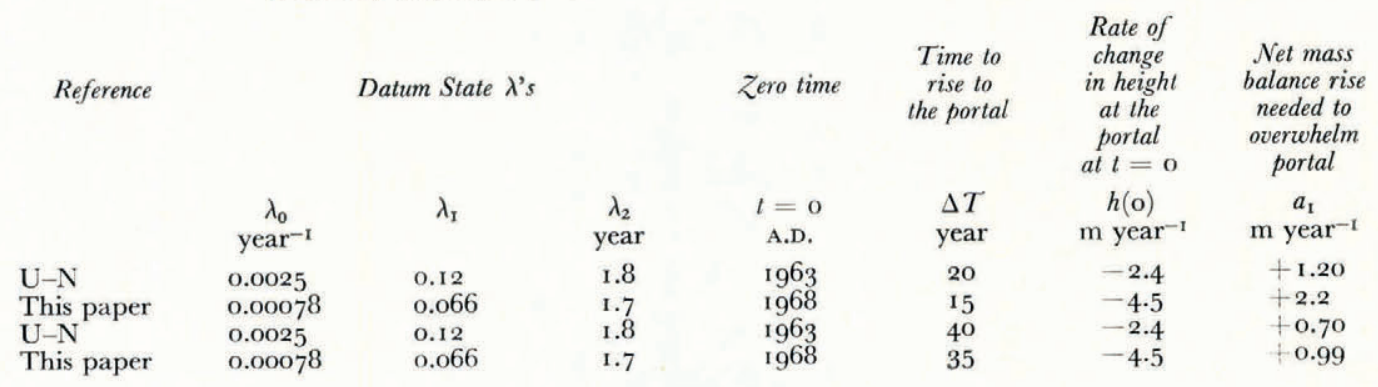

problem is to assess the likelihood that $h_{\mathrm{I}}$ at the portal will reach a critical level within a specified time. U-N took 1963 as their reference time, $t=0$, and specified times of 20 and 40 years. We took 1968 as our zero time and specified times of 15 and 35 years to compensate for the five-year difference. Moreover, whereas U-N considered that in 1963 the ice had to rise $19 \mathrm{~m}$ to overwhelm the portal, we considered a rise of $35 \mathrm{~m}$ was necessary from its $\mathrm{I} 968$ level. Our procedure was the same as U-N, namely, to assume a polynomial in $t$ for $h_{\mathrm{I}}(t)$ that is (a) consistent with what is known about $h_{\mathrm{I}}$ in 1968 and (b) will make $h_{1}(t)$ have the critical value $35 \mathrm{~m}$ at a time 35 (or I $_{5}$ ) years later. We then use Equation (2) to compute the corresponding function $a_{\mathrm{I}}(t)$, and assess the likelihood of such a variation in the light of the mass-balance data.

From the topographic maps we deduced that the ice thickness in the region under consideration was diminishing by about $4.5 \mathrm{~m} /$ year. (U-N used $2.4 \mathrm{~m} /$ year.) Thus, taking $t=0$ in 1968 , we have $h_{\mathrm{I}}(\mathrm{o})=\mathrm{o}$ (by definition), $\dot{h}_{\mathrm{I}}(\mathrm{o})=-4.5 \mathrm{~m} /$ year, $h_{\mathrm{I}}(35)=35 \mathrm{~m}$. The simplest polynomial function $h_{\mathrm{I}}(t)$ consistent with this information is (curve $\mathrm{L}_{\mathrm{I}}$ in Figure 2)

$$
h_{\mathrm{I}}(t)=p_{\mathrm{I}} t+p_{2} t^{2},
$$

where $p_{1}$ and $p_{2}$ are constants that can be determined. Then

$$
\dot{h}_{\mathrm{I}}(t)=p_{\mathrm{I}}+2 p_{2} t, \quad \ddot{h}_{\mathrm{1}}(t)=2 p_{2},
$$

and all higher derivatives are zero. So, substituting this in Equation (2) and using the values of the $\lambda$ 's and $p$ 's we find

$$
a_{\mathrm{I}}(t)=+0.237+0.0 \mathrm{I} 7 t+0.000 \mathrm{I} 2 t^{2}
$$


in units of metres and years. This is an almost linear variation in $a_{\mathrm{I}}$ from the value $+0.24 \mathrm{~m} /$ year at $t=0$ to $+0.99 \mathrm{~m} /$ year at $t=35$ years (curve $\mathrm{B}_{1}$ in Figure 2 ). When the calculation is repeated with the postulate that the ice reaches the critical level in 15 years instead of 35 years, the resulting curves are shown in $\mathrm{L}_{2}$ and $\mathrm{B}_{2}$ of Figure 2. Table II summarizes the results of this paper and compares them with U-N's. It can be seen that the required values that $a_{1}(t)$ should attain by 1983 and 2003 to cause the portal to be buried are somewhat greater in the present calculation although we did require the glacier to

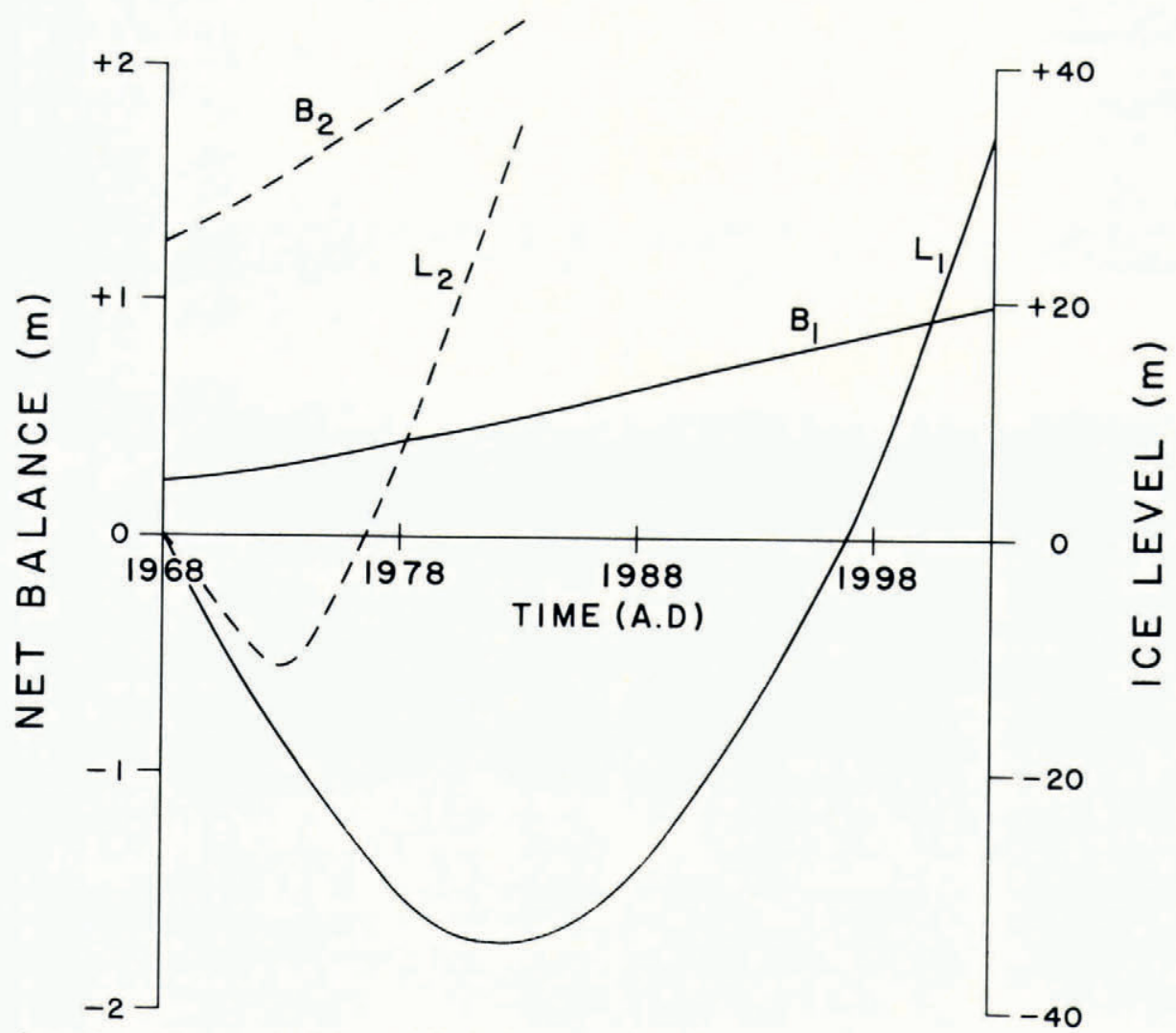

Fig. 2. Curves $L_{1}$ and $L_{2}$ : postulated change in ice level near tunnel portal. Ice reaches portal in 35 and ${ }_{15}$ years respectively. Curves $B_{1}$ and $B_{2}$ : calculated mean mass balances corresponding to curves $L_{1}$ and $L_{2}$.

respond slightly more quickly, and by a somewhat greater amount, than did U-N. However, U-N thought such a deterioration in climate unlikely whereas our data give a mean mass balance for $1967 / 68$ and $1968 / 69$ of $+0.72 \mathrm{~m} /$ year, and there has been a steady thickening in the accumulation basin since observations were begun in I963 (W. H. Mathews, private communication in 1969). Stanley (in press) gives a mass balance of $+0.78 \mathrm{~m} /$ year but this was calculated in a slightly different way and so the two values are considered to be in agreement. If our value of $+0.72 \mathrm{~m} /$ year persists, we calculate that the ice level will reach the portal in about 1994.*

${ }^{*}$ Note added in proof. Preliminary results for $1969 / 70$ indicate a mean mass balance of about $+1 \cdot 3 \mathrm{~m}$. This value falls close to our $\mathrm{B}_{2}$ curve of Figure 2. 


\section{SENSITIVITY OF THE PREDICTED RESPONSE TO THE DATUM STATE CHOSEN}

The major difference between the datum states used by $\mathrm{U}-\mathrm{N}$ and the present authors was in the velocity values used, as mentioned earlier. On average, our velocities were 1.5 times smaller than U-N's although $u_{0}(L)$ was $2.0 \mathrm{~m} /$ year in this calculation against U-N's $0.7 \mathrm{~m} /$ year. The response of the terminus is directly related to $u_{0}(L)\left(\right.$ via $\left.\mathbf{c}_{0}(L)\right)$ and an error in $\mathbf{c}_{0}(L)$ leads directly to an equal percentage error in the calculated response. But we were not interested in the response of the terminus $(x=8900)$ but at $x=8550 \mathrm{~m}$ where the value chosen for $\mathbf{c}_{0}(L)$ is not so important. Figure 3 shows the computed response of the glacier to a unit pulse in $a_{\mathrm{I}}(t)$ and can be compared with U-N's figure $3 \mathrm{a}, \mathrm{p}$. $2 \mathrm{II}$. The response at $x / L=0.96$ is close to the mine portal position and the main difference between U-N's value and Figure 3 is the time of the maximum peak which is 60 years in our work and about 35 years in U-N. This is almost entirely due to the smaller velocity figure that we used, because the velocity of a kinematic wave is directly proportional to the ice velocity.

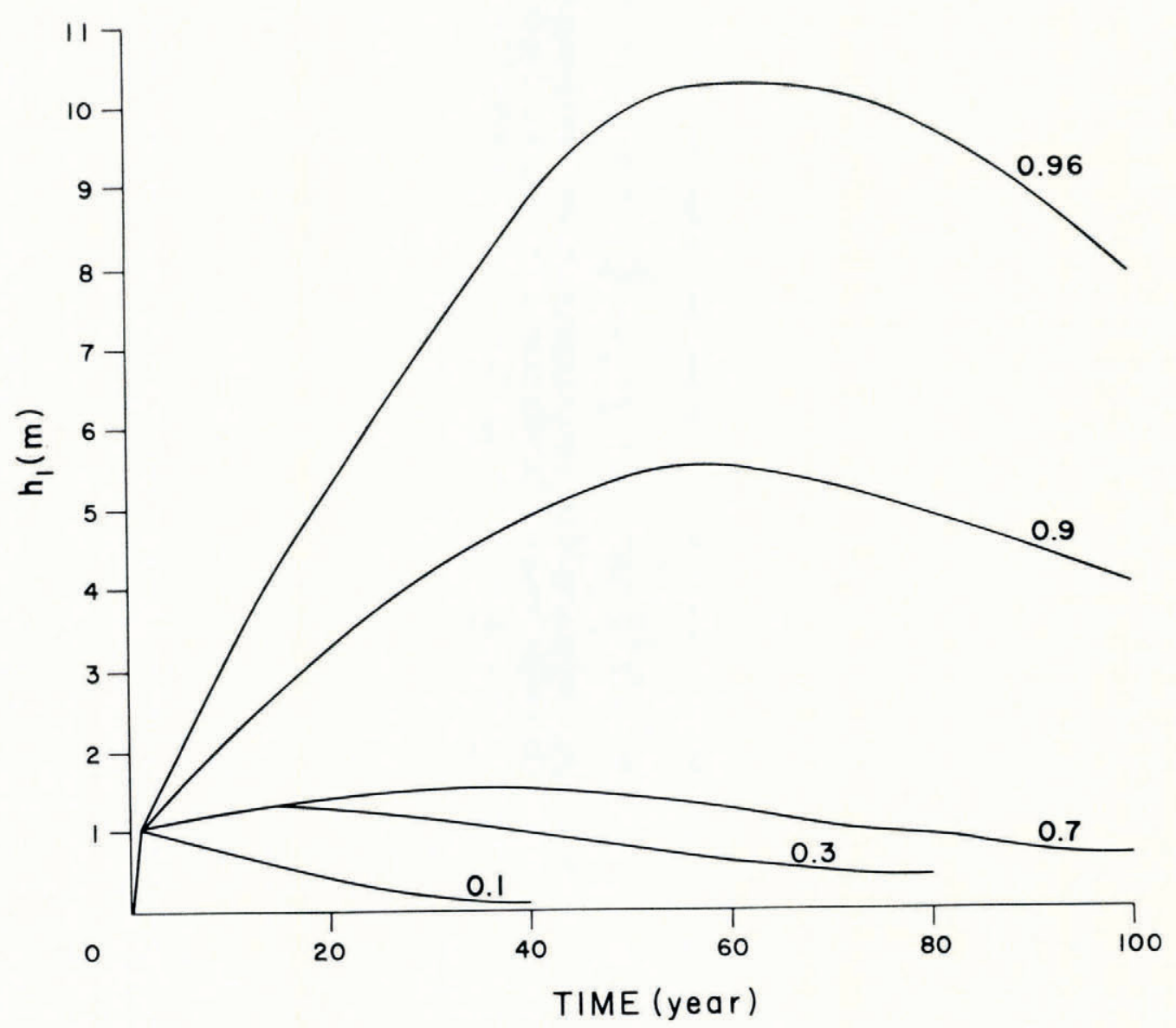

Fig. 3. Computed response of Berendon Glacier to a unit pulse. $h_{\mathrm{I}}$ is the increase of thickness in metres. The mean balance was taken as $+I m /$ year from $t=0$ to $t=I$ year and zero at other times. Numbers against the curves refer to the values of $x / L$. For points higher up glacier than $x / L \approx 0.15$ the initial increment in thickness begins to decay at once. For points lower down the glacier a flood wave builds up and then decays. 
In order to see how sensitive the predicted response is to changes in the input data, the programs were run with experimental datum states constructed with the I968 datum as a basis. In calculating the $\lambda$ 's the I 968 datum state data were altered in a number of ways:

I. By putting in U-N's $\mathbf{D}_{0}(x)$ function, or equivalently using their $a_{0}(x)$ function.

2. By putting in U-N's $\mathbf{c}_{0}(x)$ or equivalently using their $u_{0}(x)$ function, but keeping $\mathbf{c}_{0}(L)=$ 2.o.

3. By putting in values of $\mathbf{c}_{0}(x)$ equal to the 1968 values near $x=0$ and $x=L$ but equal to a constant value for all other values of $x$. The constant value was the average of the 1968 $\mathbf{c}_{0}(x)$ function.

4. By putting in an $a_{0}(x)$ different from the $\mathrm{U}-\mathrm{N}$ and the $\mathrm{i} 968$ function. The $\mathrm{U}-\mathrm{N}$ and I 968 $a_{0}(x)$ resulted in very nearly the same ice discharge $\mathbf{q}_{0}(x)$, while this trial mass balance function gave a $\mathbf{q}_{0}(x)$ approximately twice that of $\mathrm{U}-\mathrm{N}$ and the 1968 datum state.

Of all these experimental datum states only (2) gave $\lambda$ 's significantly different from those of the I 968 datum state and even then the required future values of $a_{1}$ in 2003 were all between 0.5 and $\mathrm{I} . \mathrm{I} \mathrm{m}$ year ${ }^{-1}$.

The same experimental data were used to calculate the response to a unit pulse. Only (2) gave a response markedly different from that represented in figure 3 for the I 968 datum state. The maxima at $X / L=0.96$ all occurred close to $t=60$ years except (2) where the maximum was 47 years after the end of the pulse. This was because, as mentioned earlier, U-N's velocities were on average 1.5 times greater than ours.

From using these different experimental datum states it was concluded that the results were most sensitive to the $u_{0}(x)$ function, but also it seemed that detailed knowledge of the velocities was not necessary for this type of calculation. Knowing $u_{0}(x)$ near $x=0, x=L$ and having an idea of its average value in between seemed to be adequate. Similarly, details of $a_{0}(x)$ did not appear necessary for these calculations. The results were rather insensitive to variations in $a_{0}(x)$ and probably a straight-line approximation of $a_{0}(x)$ would produce all the details reported above. However, a detailed knowledge of $a(x)$ is still needed to calculate the net balance.

It follows, of course, that the main cause for uncertainty in making predictions was the $u_{0}(x)$ function. The method used to find it from the measured values of $u(x)$ was indirect and although the values were reasonable, it would have been reassuring to have had some measured ice depths from which we could obtain valley profiles $S(x)$, and obtain $u_{0}(x)$ from $u_{0}(x)=\mathbf{q}_{0}(x) / S_{0}(x)$, making the assumption that $S(x)$ and $S_{0}(x)$ did not greatly differ.

\section{Conclusions}

The predicted response of Berendon Glacier calculated using a considerable amount of field measurements is similar to that found by $\mathrm{U}-\mathrm{N}$ using very little data. For the mine portal to be buried by 2003 A.D., $\mathrm{U}-\mathrm{N}$ predicts that the net balance must rise to $0.70 \mathrm{~m} /$ year, while we predict it has to rise to $0.99 \mathrm{~m} /$ year. Our field measurements, however, show that the 1968 mean mass balance is $+0.72 \mathrm{~m} /$ year, rather than close to zero (for 1963 ) as was thought by $\mathrm{U}-\mathrm{N}$. It is concluded, therefore, that there is a much greater chance of the portal being buried in the mid-r99o's, than was thought by $\mathrm{U}-\mathrm{N}$.

The theory is shown to be most sensitive to changes in the velocity figures used, $u_{0}(x)$, although a detailed knowledge of $u_{0}(x)$ is probably unnecessary. Similarly a detailed knowledge of mass balance is not necessary to set up the datum state, although the mean mass balance is needed to compare with the final prediction.

\section{Acknowledgements}

We would like to thank the many people who collected the necessary field data, without which this paper could not have been written. In particular we thank Mr R.J. Rogerson and 
Dr A. D. Stanley for allowing us to use their unpublished results. We are grateful to Professor J. F. Nye, University of Bristol, England, for his comments on an early draft of this manuscript, and for kindly supplying a copy of his computer programs.

MS. received 21 April 1970 and in revised form 17 July 1970

\section{REFERENCES}

Nye, J. F. 1960. The response of glaciers and ice-sheets to seasonal and climatic changes. Proceedings of the Royal Society, Ser. A, Vol. 256 , No. 1287 , p. $559-84$.

Nye, J. F. rg63[a]. On the theory of the advance and retreat of glaciers. Geophysical fournal of the Royal Astronomical Society, Vol. 7, No. 4, p. 431-56.

Nye, J. F. ${ }_{1963}[\mathrm{~b}]$. The response of a glacier to changes in the rate of nourishment and wastage. Proceedings of the Royal Society, Ser. A, Vol. 275, No. 1360, p. 87-1 12.

Nye, J. F. $1965[\mathrm{a}]$. The flow of a glacier in a channel of rectangular, elliptic or parabolic cross-section. Fournal of Glaciology, Vol. 5, No. 4r, p. 66I-90.

Nye, J. F. 1965[b]. The frequency response of glaciers. Journal of Glaciology, Vol. 5, No. 41, p. 567-87.

Nye, J. F. I $965[\mathrm{c}]$. A numerical method of inferring the budget history of a glacier from its advance and retreat. Fournal of Glaciology, Vol. 5, No. 41, p. 589-607.

Rogerson, R. J. In press. Mass water balance measurements and meteorological observations at Berendon Glacier, British Columbia - summer 1968. (In Stanley, A. D., ed. Mass water balance measurements and meteorological observations at selected glacier basins in the Canadian Cordillera for 1967-1968. Canada. Dept. of Energy, Mines and Resources. Inland Waters Branch. Technical Bulletin.)

Stanley, A. D. In press. Mass water balance measurements and meteorological observations at selected glacier basins in the Canadian Cordillera for 1968-1969. Canada. Dept. of Energy, Mines and Resources. Inland Waters Branch. Technical Bulletin.

Untersteiner, N., and Nye, J. F. 1968. Computations of the possible future behaviour of Berendon Glacier, Canada. Journal of Glaciology, Vol. 7, No. 50, p. $205^{-1} 3$. 